\title{
Extraction of polysaccharides by autohydrolysis of spent coffee grounds and evaluation of their antioxidant activity
}

\author{
Lina F. Ballesteros ${ }^{\mathrm{a}}$, José A. Teixeira ${ }^{\mathrm{a}}$, Solange I. Mussatto ${ }^{\mathrm{b}, *}$ \\ a Centre of Biological Engineering, University of Minho, Campus Gualtar, 4710-057 Braga, Portugal \\ ${ }^{\mathrm{b}}$ Department of Biotechnology, Delft University of Technology, Van der Maasweg 9, 2629 HZ Delft, The Netherlands
}

\section{A R T I C L E I N F O}

\section{Article history:}

Received 19 March 2016

Received in revised form 9 September 2016

Accepted 15 September 2016

Available online 15 September 2016

\section{Keywords:}

Spent coffee grounds

Autohydrolysis

Polysaccharides

Antioxidant activity

Structural properties

\begin{abstract}
A B S T R A C T
The extraction of polysaccharides by autohydrolysis of spent coffee grounds (SCG) was studied. Experimental assays were performed using different temperatures $\left(160-200^{\circ} \mathrm{C}\right)$, liquid/solid ratios $(5-15 \mathrm{ml}$ water/g SCG) and extraction times (10-50 min) in order to determine the conditions that maximize the extraction of polysaccharides with high antioxidant activity. Autohydrolysis was demonstrated to be an efficient technique to recover antioxidant polysaccharides from SCG. The best process conditions consisted in using $15 \mathrm{ml}$ water/g SCG, during $10 \mathrm{~min}$ at $160^{\circ} \mathrm{C}$. The polysaccharides obtained under these conditions were mainly in the form of galactomannans and arabinogalactans. They presented high antioxidant activity (assessed by four different methods), were thermostable in a large range of temperature, and had a typical carbohydrate pattern, being of interest for industrial applications, mainly in the food area.
\end{abstract}

@ 2016 Elsevier Ltd. All rights reserved.

\section{Introduction}

Coffee, being one of the most popular and appreciated beverages around the world, is considered an important source of polysaccharides, mainly galactomannans, arabinogalactans, and cellulose (Arya \& Rao, 2007; Ballesteros, Teixeira, \& Mussatto, 2014a; Mussatto, Machado, Martins, \& Teixeira, 2011; Nunes, Domingues, \& Coimbra, 2005). Coffee galactomannans are composed of a backbone of $\beta$ - $(1 \rightarrow 4)$-linked mannose residues containing single galactose side groups with different degrees of branching (Nunes et al., 2005). They are high molecular weight polysaccharides and show a low level of branching. Nonetheless, the roasting process influences on the depolymerization and debranching of galactomannans, increasing thus, their extraction and solubility in water (Simões, Maricato, Nunes, Domingues, \& Coimbra, 2014). On the other hand, coffee type II arabinogalactans are also high molecular weight polysaccharides, highly branched, composed of a backbone of $\beta-(1 \rightarrow 3)$-linked galactose residues and side chains of galactose and arabinose residues (Passos \& Coimbra, 2013). Due to their structure, arabinogalactans are the coffee polysaccharides most expose to degradation during the roasting and the arabinose side chains are the first in to be hydrolyzed (Oosterveld, Harmsen, Voragen, \&

\footnotetext{
* Corresponding author.

E-mail addresses: S.I.Mussatto@tudelft.nl, solangemussatto@hotmail.com (S.I. Mussatto).
}

Schols, 2003). Both, galactomannans and arabinogalactans strongly affect the quality and properties of the final beverage. However, the majority of them (around 70\% of total polysaccharides from roasted coffee) (Arya \& Rao, 2007) remain in the residue generated after soluble coffee preparation, named as spent coffee grounds (SCG).

Currently, there is an especial interest in the use of non-digestible polysaccharides obtained from natural sources, including coffee and its wastes. Some findings have shown the antimicrobial and antioxidant capacities of polysaccharides extracted from SCG (Ballesteros, Cerqueira, Teixeira, \& Mussatto, 2015) and the immunostimulatory properties provided by coffee galactomannans (Simões et al., 2009) and arabinogalactans (Gotoda et al., 2007). The prebiotic potential of coffee residue mannans has been also proved since it improves the health of human intestinal microflora (Asano et al., 2001; Gniechwitz, Reichardt, Blaut, Steinhart, \& Bunzel, 2007).

The extraction of polysaccharides from SCG has been studied through different methods, mainly using chemicals as extraction agents. Sodium hydroxide (Ballesteros et al., 2015; Simões, Nunes, Maria do Rosário, \& Coimbra, 2010; Simões et al., 2009) and potassium hydroxide (Fischer, Reimann, Trovato, \& Redgwell, 2001), for example, have been employed in alkali treatments, while sulfuric acid has been used to recover carbohydrates by dilute acid hydrolysis of SCG (Mussatto, Carneiro, Silva, Roberto, \& Teixeira, 2011).

Autohydrolysis is an eco-friendly technology that does not require the use of chemical agents for reaction. This technique has been used to extract polysaccharides from different natural sources 
such as Eucalyptus globulus wood (Romaní, Garrote, López, \& Parajó, 2011), Pinus pinaster wood and rice husks (Rivas, Conde, Moure, Domínguez, \& Parajó, 2013), among others. During autohydrolysis, a slightly acid medium is obtained due to the partial release of acetyl groups from the material structure, providing a selective depolymerization of the hemicellulose (Nabarlatz, Ebringerová, \& Montané, 2007). Autohydrolysis of lignocellulosic materials is a complex process since many factors such as the liquid/solid ratio, temperature, particle size of the solid matrix, the extraction time, as well as the structure and polymerization degree of molecules and their interaction with proteins, minerals, and phenolic compounds can influence in the reaction efficiency. Taking these facts into account, the purpose of the present study was to evaluate the extraction of polysaccharides from SCG by using the environmentally friendly technique of autohydrolysis. Assays were performed using different temperatures, liquid/solid ratios and extraction times, and the effects of these operational variables on the extraction yield and antioxidant activity of the recovered polysaccharides were verified. The polysaccharides obtained under the best autohydrolysis conditions were chemically and structurally characterized.

\section{Materials and methods}

\subsection{Raw material and chemicals}

Spent coffee grounds (SCG) were provided by the Portuguese coffee industry NovaDelta-Comércio e Indústria de Cafés S.A. (Campo Maior, Portugal). The material was dried in an oven at $60^{\circ} \mathrm{C}$ until $5 \%$ moisture content and stored for further extractions. All the chemicals used were an analytical grade, purchased from Panreac Química (Barcelona, Spain), Fisher Scientific (Leicestershire, UK) and Sigma-Aldrich (Chemie GmbH, Steinheim, Germany). Ultrapure water from a Milli-Q System (Millipore Inc., USA) was used.

\subsection{Autohydrolysis}

Autohydrolysis assays were performed under different conditions of temperature $\left(160-200^{\circ} \mathrm{C}\right)$, liquid/solid ratio $(5-15 \mathrm{ml}$ water/g SCG) and extraction time (10-50 min), which were combined according to a $2^{3}$ central composite design. For the reactions, ultrapure water, and the SCG were poured into $160-\mathrm{ml}$ cylindrical stainless steel reactors (Parr Instruments Company, Illinois, USA), which were duly closed and placed vertically into an oil-bath with an open heating circulator and temperature control (Julabo, Labortechnik GmbH, Seelbach, Germany). The samples were left in the bath, previously heated until the desired temperature, during the time required for each reaction. Then, the reactors were removed from the oil-batch and immediately cooled down in an ice-bath for $10 \mathrm{~min}$ to stop the reaction. The total content of each reactor was centrifuged ( $2500 \mathrm{~g}, 20 \mathrm{~min}$ ) being the supernatant separated and treated to recover the polysaccharides present.

\subsection{Polysaccharides recovery}

In order to recover the polysaccharides present in the liquid fractions obtained after autohydrolysis of SCG, $30 \mathrm{ml}$ of supernatant were mixed with absolute ethanol in a $1: 3(\mathrm{v} / \mathrm{v})$ ratio and the mixture was left overnight at $4{ }^{\circ} \mathrm{C}$. The precipitated polysaccharides were recovered by centrifugation $(2500 \mathrm{~g}, 20 \mathrm{~min})$, hydrated with $30 \mathrm{ml}$ distilled water and maintained in a shaker during $3 \mathrm{~h}$, at $200 \mathrm{rpm}$ and room temperature. Subsequently, the mixture was again centrifuged and the supernatant was frozen and freeze-dried. Freeze-dried powder was stored at room temperature and protected from light and humidity until further use. The total yield of the extraction process was expressed as mg of lyophilized material per g SCG (mg LM/g SCG).

\subsection{Analytical methodology}

For evaluating the properties of the polysaccharides recovered from SCG, ultrapure water and, the lyophilized material were mixed to obtain $1.5 \mathrm{mg} / \mathrm{ml}$. The samples were vortexed for $1 \mathrm{~min}$, filtered through $0.22 \mu \mathrm{m}$ filters and then stored for analyses.

\subsubsection{Total sugars}

The content of total sugars was determined by the anthronesulfuric acid assay. Briefly, a $50 \mu \mathrm{l}$ aliquot of the sample (LM at $1.5 \mathrm{mg} / \mathrm{ml}$ ) was mixed with $150 \mu \mathrm{l}$ of anthrone reagent in a 96-well microplate. Then, the reaction mixture was placed at $4{ }^{\circ} \mathrm{C}$ for $10 \mathrm{~min}$ and was subsequently incubated at $100^{\circ} \mathrm{C}$ for $20 \mathrm{~min}$. After heating, the samples were allowed to cool down at room temperature for $20 \mathrm{~min}$. The absorbance was determined in a spectrophotometer microplate reader (Sunrise Tecan, Grödig, Austria) set at $620 \mathrm{~nm}$ and using distilled water as blank. The anthrone reagent was prepared immediately prior to analysis by dissolving $0.1 \mathrm{~g}$ of anthrone in $100 \mathrm{ml}$ of concentrated sulfuric acid (98\%), protected from light and used within $12 \mathrm{~h}$. A calibration curve was performed using a standard glucose solution $(10,60,120,200,250,300,400$ and $600 \mu \mathrm{g} / \mathrm{ml}$ ). The content of total sugars was expressed as grams glucose equivalent per $100 \mathrm{~g}$ of lyophilized material ( $\mathrm{g} \mathrm{GLU} / 100 \mathrm{~g}$ LM).

\subsubsection{Phenolic compounds}

The content of phenolic compounds (PC) was determined by using the Folin-Ciocalteu reagent method adapted to a 96-well microplate (Ballesteros, Teixeira, \& Mussatto, 2014b), and was expressed as milligrams of gallic acid equivalent per $\mathrm{g}$ of lyophilized material (mg GAE/g LM).

\subsubsection{Reducing sugars}

The content of reducing sugars (RS) was estimated by the colorimetric method of DNS (3,5-dinitrosalicylic acid) adapted to a 96-well microplate. Briefly, $25 \mu \mathrm{l}$ of the sample (LM at $1.5 \mathrm{mg} / \mathrm{ml}$ ) were mixed with $25 \mu$ l of DNS reagent and incubated at $100^{\circ} \mathrm{C}$ for $10 \mathrm{~min}$. Thereafter, $250 \mu \mathrm{l}$ of distilled water were added to each well and the microplate was placed on an ice-bath to stop the reaction. The absorbance was determined in a spectrophotometer microplate reader (Sunrise Tecan, Grödig, Austria) set at $540 \mathrm{~nm}$, using distilled water as blank. DNS reagent was freshly prepared by dissolving $2.5 \mathrm{~g}$ of 3,5-dinitrosalicylic acid in $25 \mathrm{ml}$ of distilled water preheated at $80^{\circ} \mathrm{C}$. The solution was cooled at room temperature, and after, $50 \mathrm{ml}$ of a $2 \mathrm{~N}$ sodium hydroxide solution and $75 \mathrm{~g}$ of potassium sodium tartrate were added being the final volume completed to $250 \mathrm{ml}$ with distilled water. A standard calibration curve was prepared using glucose solution $(0.2,0.4,0.6,0.8,1.0 .1 .2,1.4$, 1.6 , and $1.8 \mathrm{mg} / \mathrm{ml}$ ). The content of RS was expressed as milligrams glucose equivalent per $\mathrm{g}$ of lyophilized material (mg GLU/g LM).

\subsubsection{Antioxidant activity}

The antioxidant activity of the polysaccharides was estimated by four different methods as described by Ballesteros et al. (2015) and Ballesteros et al. (2014b): Total antioxidant activity (TAA), DPPH radical scavenging activity assay, the radical cation decolorization (ABTS) assay, and the ferric reducing antioxidant power (FRAP) assay. TAA values were expressed as milligrams of $\alpha$-tocopherol equivalent per $g$ of lyophilized material (mg $\alpha$-TOC/g LM). DPPH and ABTS data were plotted as a function of antioxidant concentration to obtain DPPH and ABTS inhibition concentration at $50 \%\left(\mathrm{IC}_{50}\right)$. The $\mathrm{IC}_{50}$ values were expressed as micromoles of Trolox equivalent per $g$ of lyophilized material ( $\mu$ mol TE/g LM). FRAP values were 
expressed as millimoles of ferrous equivalent per $\mathrm{g}$ of lyophilized material (mmol Fe(II)/g LM).

\subsection{Experimental design and data analysis}

The influence of the independent variables, temperature $\left(X_{1}\right.$, $\left.{ }^{\circ} \mathrm{C}\right)$, liquid/solid ratio $\left(\mathrm{X}_{2}, \mathrm{ml} / \mathrm{g}\right)$ and extraction time $\left(\mathrm{X}_{3}, \mathrm{~min}\right)$, on the extraction of polysaccharides by autohydrolysis of SCG, was evaluated through a $2^{3}$ central composite design. The real and coded values of the variables are shown in Table 1 . Statistical significance of the variables was determined at $5 \%$ probability level $(p<0.05)$. The data obtained from the design were fitted to second-order polynomial equations, and the models were simplified by elimination of statistically insignificant terms. Statistical significance of the regression coefficients was determined by Student's $t$-test, and the proportion of variance explained by the models were given by the multiple coefficients of determination, $\mathrm{R}^{2}$. Statistical analysis of the data and the determination of the conditions able to maximize the extraction of polysaccharides with high antioxidant activity were performed using the software Design expert (version 8.0).

\subsection{Polysaccharide characterization}

\subsubsection{Sugars composition}

The extracted polysaccharides were submitted to a dilute acid hydrolysis with sulfuric acid $\left(120 \mathrm{mg} \mathrm{H}_{2} \mathrm{SO}_{4} / \mathrm{g} \mathrm{LM}\right)$ at $120^{\circ} \mathrm{C}$ for $20 \mathrm{~min}$. The resulting solution was analyzed by high-performance liquid chromatography (HPLC) (Ballesteros et al., 2015). Glucose, arabinose, galactose, and mannose were identified and quantified from standard curves made with known concentrations of each compound and expressed as\% mol.

\subsubsection{Structural characterization}

Crystalline phases and the chemical groups and bonding arrangement of constituents present in the polysaccharides were evaluated by X-ray diffraction (XRD) and Fourier transform infrared spectroscopy (FTIR), respectively, as described by Ballesteros et al. (2014a). Differential scanning calorimetry (DSC) was performed in equipment DSC 200 F3 Maia (Netzsch, Germany) and thermogravimetric analyses (TGA) were carried out in equipment SDT 2960 simultaneous DSC-TGA (TA instruments, USA). For the analyses, approx. $5 \mathrm{mg}$ of the sample were placed in an aluminum pan. The measurements were carried out between 25 and $600^{\circ} \mathrm{C}$ with a linear increase of $10^{\circ} \mathrm{C}$ per min. TA Universal Analysis software (TA instruments, universal analysis 2000, USA) was used for data analysis. Enthalpy was calculated using the area of the peaks between the onset and the end set temperatures.

\section{Results and discussion}

\subsection{Extraction results}

Autohydrolysis technique has been widely used for the extraction of polysaccharides, especially hemicelluloses from natural sources. Although this technique causes a selective depolymerization of hemicellulose chains for oligosaccharides and monosaccharides sugars, other components such as PC (derived from lignin) may also appear in the reaction medium (Clark \& Mackie, 1984). Therefore, the present study evaluated the effect of different process variables including temperature, liquid/solid ratio and extraction time on the recovery of polysaccharides from SCG in order to select the conditions that maximize the polysaccharides extraction yield. The content of PC in the recovered lyophilized material was also quantified.

Table 1 shows the experimental conditions used in each assay and the respective results of total sugars, PC, RS, FRAP, DPPH, ABTS,
TAA and total yield of the extraction process. As it can be seen, polysaccharides were extracted from SCG in all the studied conditions, however, the extraction yield greatly varied according to the conditions used. In terms of composition, the highest amount of total sugars in the LM corresponded to $34.92 \%(\mathrm{w} / \mathrm{w})$ and was achieved when using a liquid/solid ratio of $15 \mathrm{ml} / \mathrm{g}$ SCG during 30 min at $180^{\circ} \mathrm{C}$ (assay 14 ); while the lowest amount of total sugars $(15.16 \%(\mathrm{w} / \mathrm{w}))$ was obtained when using $10 \mathrm{ml} / \mathrm{g} \mathrm{SCG}$, at $160^{\circ} \mathrm{C}$ and 30 min (assay 9). In general, the results were increased when the values of the variables were raised, but this behavior was observed until a certain limit only. When the temperature was increased to $200^{\circ} \mathrm{C}$, for example, the quantity of total sugars was lower than when intermediate conditions were applied. This could be related to the fact that when the highest temperature was used, a stronger hydrolysis of polysaccharides and subsequent degradation of these components might have occurred.

The content of PC in the lyophilized material varied between $82.33 \pm 1.63$ (assay 8 ) and $254.00 \pm 1.86 \mathrm{mg} \mathrm{GAE} / \mathrm{g} \mathrm{LM}$ (assay 11). It is worth highlighting that the highest amount of PC recovered by autohydrolysis of SCG $(254.00 \pm 1.86 \mathrm{mg} \mathrm{GAE} / \mathrm{g} \mathrm{LM})$ in the present study was greater than the value previously reported by Ballesteros et al. (2015) by alkali pretreatment of this same feedstock $(230 \mathrm{mg}$ GAE/g LM). These results indicate autohydrolysis as an efficient technique to extract also PC from SCG.

The content of RS in the lyophilized material was also dependent on the conditions used for autohydrolysis, being observed values in the range between $12.96 \pm 0.92$ (assay 8) and $93.93 \pm 4.44 \mathrm{mg}$ GLU/g LM (assay 5)(Table 1). Such results reveal that in some cases a significant part of the recovered polysaccharides were in the form of monosaccharides, as for example in the assays 9 (52\%) and 11 (51\%). It is important to mention that, previous the precipitation stage, the largest amount of RS had been found in the extract obtained during autohydrolysis at $200^{\circ} \mathrm{C}, 15 \mathrm{ml} / \mathrm{g} \mathrm{SCG}, 50 \mathrm{~min}$ (not presented data). Nonetheless, after precipitation stage, the greatest amount of RS was recovered in the LM obtained when the lowest conditions of temperature and extraction time were used for autohydrolysis $\left(160^{\circ} \mathrm{C}, 10 \mathrm{~min}\right.$, and $15 \mathrm{ml} / \mathrm{g} \mathrm{SCG}$ - assay 5$)$. The same behavior was observed for PC and the antioxidant activity results, explained by the fact that the precipitation recovers the high molecular weight compounds, and thus, to the lowest temperature and extraction time, the polysaccharides with high antioxidant activity were less hydrolyzed than those summited to the highest extraction conditions. These results suggest that the compounds extracted under these conditions had a higher molecular weight, achieving thus, the precipitation with ethanol.

The antioxidant activity of the recovered polysaccharides was also strongly affected by the conditions used for autohydrolysis (Table 1). By varying the extraction conditions, the TAA and FRAP results were increased in the order of 2.5-fold and 3.5-fold, respectively. More significant variations were observed in the DPPH and ABTS results, which increased in almost 4-fold. Differences between the results of antioxidant assays could be explained by the fact that the methods differ from each other in terms of reaction mechanisms, oxidant and target/probe species, and reaction conditions (Conde \& Mussatto, 2016). Therefore it is of great importance to assess the antioxidant potential by using different methodologies.

All antioxidant activity methods (FRAP, DPPH, ABTS, and TAA) showed a highly significant linear correlation to PC and RS (coefficients $R^{2} \geq 0.82$ ), being found the highest correlations to DPPH data correlated with PC $\left(R^{2}=0.93\right)$ and ABTS data correlated with $R S\left(R^{2}=0.92\right)$. These results suggest that the PC and RS present in the lyophilized material contributed significantly to the antioxidant activity of the polysaccharides extracted from SCG. However, the autohydrolysis conditions that extracted the largest amount of polysaccharides from SCG were not the same that generated polysaccharides with the highest antioxidant activity (Table 1). For 
Table 1

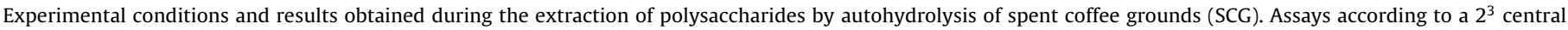
composite design.

\begin{tabular}{|c|c|c|c|c|c|c|c|c|c|c|c|}
\hline \multirow[t]{2}{*}{$\mathrm{A}^{\mathrm{a}}$} & \multicolumn{3}{|c|}{$\begin{array}{l}\text { Process variables } \\
\text { (real and (coded) values) }\end{array}$} & \multirow[t]{2}{*}{ Total sugars } & \multicolumn{7}{|l|}{ Responses $^{c}$} \\
\hline & $\mathrm{X}_{1}$ & $\mathrm{X}_{2}$ & $\mathrm{X}_{3}$ & & PC & RS & FRAP & DPPH & ABTS & TAA & Yield \\
\hline 1 & $160(-1)$ & $5(-1)$ & $10(-1)$ & $25.30 \pm 6.28$ & $239.38 \pm 2.50$ & $88.45 \pm 4.10$ & $0.70 \pm 0.02$ & $468.07 \pm 26.07$ & $532.86 \pm 15.26$ & $268.28 \pm 3.31$ & 11.81 \\
\hline 2 & $200(+1)$ & $5(-1)$ & $10(1)$ & $21.79 \pm 5.43$ & $214.14 \pm 12.08$ & $70.40 \pm 4.93$ & $0.61 \pm 0.03$ & $501.82 \pm 21.37$ & $454.60 \pm 7.15$ & $218.21 \pm 14.04$ & 20.87 \\
\hline 3 & $160(-1)$ & $5(-1)$ & $50(+1)$ & $21.42 \pm 0.80$ & $202.00 \pm 3.01$ & $59.90 \pm 4.84$ & $0.56 \pm 0.03$ & $434.26 \pm 6.67$ & $429.23 \pm 7.41$ & $187.49 \pm 12.78$ & 25.79 \\
\hline 4 & $200(+1)$ & $5(-1)$ & $50(+1)$ & $23.04 \pm 1.83$ & $103.54 \pm 3.51$ & $20.09 \pm 0.81$ & $0.26 \pm 0.02$ & $207.35 \pm 0.95$ & $202.00 \pm 2.39$ & $108.64 \pm 4.01$ & 19.32 \\
\hline 5 & $160(-1)$ & $15(+1)$ & $10(-1)$ & $28.56 \pm 3.38$ & $234.14 \pm 5.30$ & $93.93 \pm 4.44$ & $0.68 \pm 0.05$ & $515.95 \pm 7.00$ & $600.24 \pm 12.20$ & $228.46 \pm 5.03$ & 35.87 \\
\hline 6 & $200(+1)$ & $15(+1)$ & $10(-1)$ & $25.10 \pm 3.45$ & $195.14 \pm 12.98$ & $63.26 \pm 2.71$ & $0.51 \pm 0.02$ & $420.39 \pm 7.27$ & $427.74 \pm 4.42$ & $185.29 \pm 5.92$ & 42.61 \\
\hline 7 & $160(-1)$ & $15(+1)$ & $50(+1)$ & $31.19 \pm 5.56$ & $232.95 \pm 11.01$ & $76.80 \pm 3.62$ & $0.69 \pm 0.03$ & $573.93 \pm 29.96$ & $529.47 \pm 18.05$ & $254.44 \pm 3.25$ & 45.15 \\
\hline 8 & $200(+1)$ & $15(+1)$ & $50(+1)$ & $24.60 \pm 6.37$ & $82.33 \pm 1.63$ & $12.96 \pm 0.92$ & $0.20 \pm 0.01$ & $155.59 \pm 0.58$ & $144.60 \pm 0.68$ & $131.52 \pm 2.66$ & 32.62 \\
\hline 9 & $160(-1)$ & $10(0)$ & $30(0)$ & $15.16 \pm 0.92$ & $239.14 \pm 6.07$ & $78.77 \pm 2.90$ & $0.61 \pm 0.04$ & $504.45 \pm 3.25$ & $431.29 \pm 0.55$ & $255.38 \pm 4.06$ & 35.24 \\
\hline 10 & $200(+1)$ & $10(0)$ & $30(0)$ & $20.70 \pm 3.25$ & $132.95 \pm 3.25$ & $24.37 \pm 2.71$ & $0.30 \pm 0.03$ & $208.83 \pm 0.50$ & $186.97 \pm 0.85$ & $132.25 \pm 4.34$ & 80.69 \\
\hline 11 & $180(0)$ & $10(0)$ & $10(-1)$ & $17.73 \pm 2.32$ & $254.00 \pm 1.86$ & $90.39 \pm 1.76$ & $0.65 \pm 0.03$ & $596.76 \pm 3.24$ & $470.78 \pm 8.96$ & $282.67 \pm 0.38$ & 31.03 \\
\hline 12 & $180(0)$ & $10(0)$ & $50(+1)$ & $26.77 \pm 2.34$ & $156.52 \pm 8.57$ & $35.25 \pm 3.07$ & $0.43 \pm 0.01$ & $344.23 \pm 0.05$ & $261.84 \pm 2.56$ & $180.53 \pm 2.44$ & 82.95 \\
\hline 13 & $180(0)$ & $5(-1)$ & $30(0)$ & $30.32 \pm 1.08$ & $169.94 \pm 6.12$ & $41.16 \pm 2.25$ & $0.47 \pm 0.03$ & $349.95 \pm 1.66$ & $286.77 \pm 13.18$ & $192.80 \pm 4.51$ & 38.96 \\
\hline 14 & $180(0)$ & $15(+1)$ & $30(0)$ & $34.92 \pm 3.62$ & $185.81 \pm 11.02$ & $51.20 \pm 1.39$ & $0.52 \pm 0.02$ & $378.84 \pm 25.08$ & $317.88 \pm 8.93$ & $204.14 \pm 3.14$ & 89.5 \\
\hline 15 & $180(0)$ & $10(0)$ & $30(0)$ & $28.47 \pm 6.27$ & $175.71 \pm 5.29$ & $46.28 \pm 1.97$ & $0.45 \pm 0.02$ & $374.65 \pm 5.64$ & $322.60 \pm 3.81$ & $183.49 \pm 5.88$ & 56.79 \\
\hline 16 & $180(0)$ & $10(0)$ & $30(0)$ & $31.73 \pm 3.93$ & $176.05 \pm 2.50$ & $45.78 \pm 3.48$ & $0.46 \pm 0.01$ & $412.11 \pm 9.32$ & $310.85 \pm 0.53$ & $197.49 \pm 2.03$ & 57.65 \\
\hline 17 & $180(0)$ & $10(0)$ & $30(0)$ & $29.45 \pm 3.60$ & $177.48 \pm 4.29$ & $45.62 \pm 1.14$ & $0.42 \pm 0.01$ & $360.95 \pm 2.30$ & $347.41 \pm 1.63$ & $193.29 \pm 4.14$ & 55.71 \\
\hline 18 & $180(0)$ & $10(0)$ & $30(0)$ & $31.29 \pm 6.23$ & $179.14 \pm 5.71$ & $44.63 \pm 2.27$ & $0.50 \pm 0.01$ & $429.35 \pm 16.59$ & $316.22 \pm 18.63$ & $203.01 \pm 1.37$ & 57.08 \\
\hline 19 & $180(0)$ & $10(0)$ & $30(0)$ & $28.51 \pm 3.36$ & $171.29 \pm 1.63$ & $43.81 \pm 0.70$ & $0.46 \pm 0.02$ & $347.70 \pm 1.86$ & $274.72 \pm 7.47$ & $183.70 \pm 3.29$ & 60.27 \\
\hline 20 & $180(0)$ & $10(0)$ & $30(0)$ & $27.84 \pm 5.37$ & $173.75 \pm 2.40$ & $43.08 \pm 3.54$ & $0.47 \pm 0.02$ & $386.55 \pm 4.40$ & $386.75 \pm 1.53$ & $200.92 \pm 1.44$ & 62.79 \\
\hline
\end{tabular}

LM: lyophilized material.

a A: Assays.

b $\mathrm{X}_{1}$ : temperature $\left({ }^{\circ} \mathrm{C}\right) ; \mathrm{X}_{2}$ : liquid/solid ratio $(\mathrm{mL} / \mathrm{g}) ; \mathrm{X}_{3}$ : extraction time (min).

Total sugars (g GLU/100g LM); PC: phenolic compounds (mg GAE/g LM); RS: reducing sugars (mg GLU/g LM); FRAP: ferric reducing antioxidant power assay (mmol

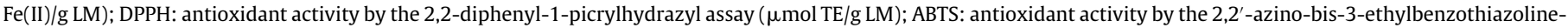
6-sulphonic acid assay ( $\mu \mathrm{mol}$ TE/g LM); TAA: total antioxidant activity ( $\mathrm{mg} \alpha$-TOC/g LM); Yield of extraction process (mg LM/g SCG).

this reason, an optimization of the process conditions is necessary in order to obtain the maximum yield of polysaccharides with high antioxidant potential.

\subsection{Statistical analysis of autohydrolysis results}

\subsubsection{Effect of operational variables}

The Pareto charts in Fig. 1 shows the effect of each operational variable on the different responses. Temperature $\left(\mathrm{X}_{1}\right)$ was the most significant variable, followed by the extraction time $\left(\mathrm{X}_{3}\right)$ on $\mathrm{PC}$ and RS (Fig. 1a and b), as well as on all the antioxidant activity responses (Fig. 1c-f). Both, temperature and extraction time exerted a significant $(p<0.05)$ and negative linear (L) effect on the responses, which means that the extraction of polysaccharides with high antioxidant activity increased when the temperature and reaction time were reduced. However, not only the linear terms but also the quadratic terms $(Q)$ and interactions between the variables had statistical significance $(p<0.05)$, suggesting that the values of the responses were not always linearly raised when the value of the operational variables was decreased. The individual effect of the liquid/solid ratio $\left(\mathrm{X}_{2}\right)$ was not significant for any of the responses, but the interaction of this variable with the temperature was significant for the antioxidant activity results.

The operational variables did not present effects significant at 95\% confidence level for the extraction yield response (Fig. 1g). However, a mathematical model describing the variations of this response as a function of the process variables could be well-fitted to a second-order polynomial equation (Table 2). Second-order mathematical models were also fitted for all the other responses. When possible, the models were simplified by elimination of terms not statistically significant $(p>0.05)$. In other cases, the nonsignificant variables were kept in the models to minimize the error determination. All the models were established with high coefficient of determinations $\mathrm{R}^{2}$, ranging from 0.87 to 0.97 , which means a close agreement between the experimental results and those predicted by the equations.
Contour lines graphs were plotted for all the responses according to the model equations established (Table 2). The plots of PC (Fig. 2a), RS (Fig. 2b) and antioxidant activities (Fig. 2c-f) show a region where the responses can be maximized, which occurs using the lowest temperature and extraction time, and $15 \mathrm{ml} / \mathrm{g}$ SCG of liquid/solid ratio. In contrast, the extraction yield of the process (Fig. $2 \mathrm{~g}$ ) is maximized when using intermediate values of temperature and extraction time in combination with the highest liquid/solid ratio ( $15 \mathrm{ml} / \mathrm{g} \mathrm{SCG}$ ).

\subsubsection{Selection of the optimum autohydrolysis conditions}

Taking into account the results obtained in the statistical analysis, a graphical optimization was performed by overlaying the curves of the models. Thus, the following criteria were adopted in order to find an extraction condition that simultaneously maximize the contents of PC and RS, as well as the antioxidant activity of the recovered polysaccharides: $\mathrm{PC} \geq 220 \mathrm{mg} \mathrm{GAE} / \mathrm{g} \mathrm{LM}, \mathrm{RS} \geq 87 \mathrm{mg}$ GLU/g LM, FRAP $\geq 0.65 \mathrm{mmol} F($ II $) / g$ LM, DPPH $\geq 510 \mu \mathrm{mol} \mathrm{TE} / \mathrm{g}$ $\mathrm{LM}, \mathrm{ABTS} \geq 550 \mu \mathrm{mol} \mathrm{TE} / \mathrm{g} \mathrm{LM}$, and TAA $\geq 225 \mathrm{mg} \alpha$-TOC/g LM. The overlaying plot attained (Fig. 3 ) shows an area where all the criteria are satisfied (shadow area). A point within this area was assigned as the optimum point, which corresponded to the use of $160^{\circ} \mathrm{C}$, $15 \mathrm{ml} / \mathrm{g} \mathrm{SCG}$ and $10 \mathrm{~min}$. Under these conditions, the model predicts PC and RS results of $246.21 \mathrm{mg} \mathrm{GAE} / \mathrm{g} \mathrm{LM}$ and $101 \mathrm{mg} \mathrm{GLU/g}$ LM, as well as antioxidant activity values for FRAP, DPPH, ABTS and TAA of $0.71 \mathrm{mmol} \mathrm{Fe}(\mathrm{II}) / \mathrm{g} \mathrm{LM}, 576.35 \mu \mathrm{mol} \mathrm{TE} / \mathrm{g} \mathrm{LM}, 605.73 \mu \mathrm{mol}$ TE/g LM and $247.04 \mathrm{mg} \alpha-\mathrm{TOC} / \mathrm{g}$ LM, respectively. These values corresponded to one of the conditions previously evaluated experimentally (Table 1 , conditions $-1,+1,-1$ ), being the responses within $5 \%$ of relative standard deviation (Fig. 3 inset). The polysaccharide obtained in this condition as well as the polysaccharide obtained under the condition that gave the best extraction yield (Table 1, assay 14) were further evaluated in order to determine their composition and structural and thermal characteristics. 
a)

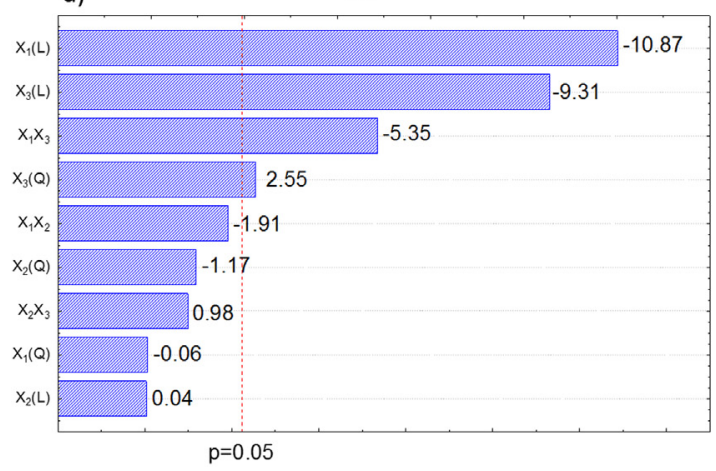

Standardized Effect Estimate (Absolute Value)

c)

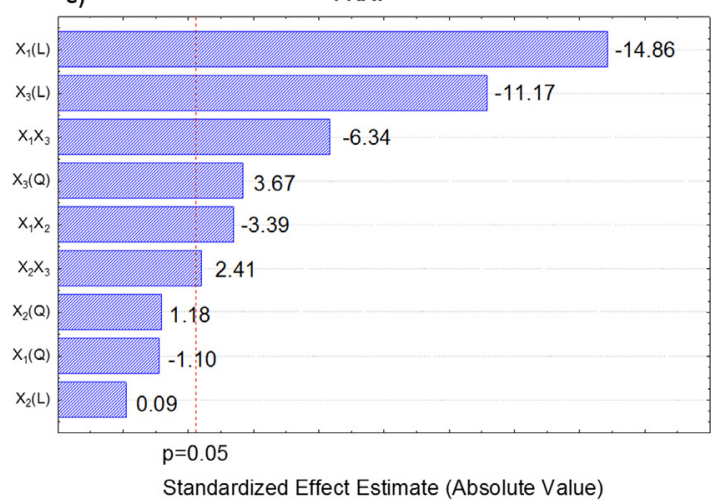

e)

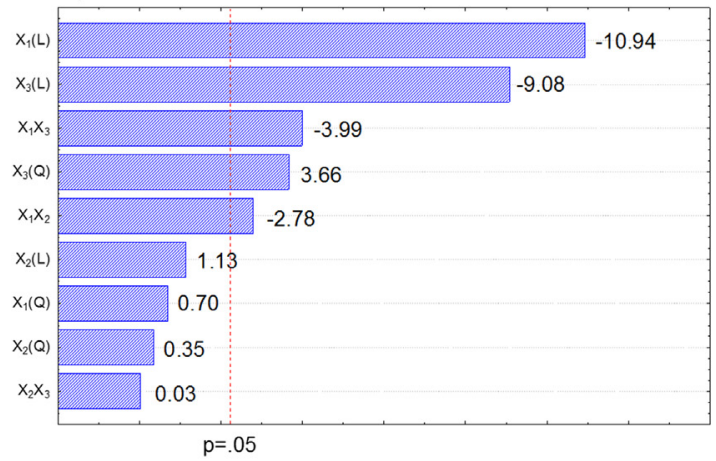

Standardized Effect Estimate (Absolute Value) b)

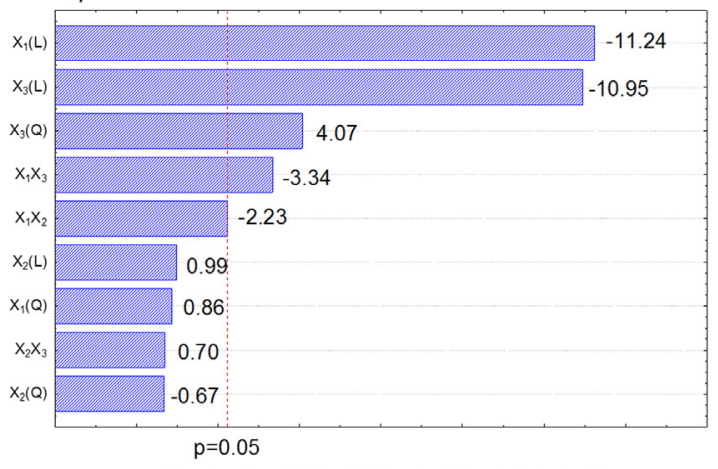

Standardized Effect Estimate (Absolute Value)

d)

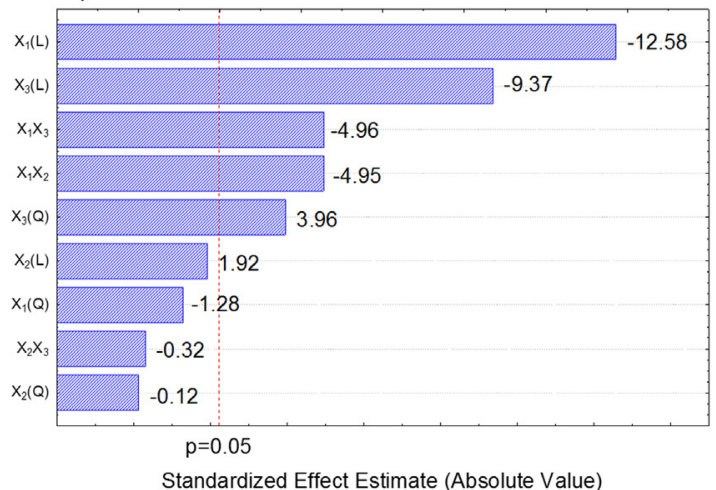

Standardized Effect Estimate (Absolute Value)
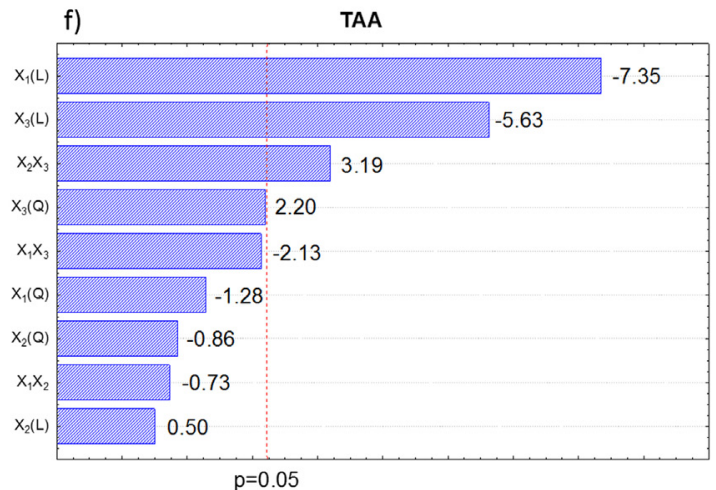

Standardized Effect Estimate (Absolute Value)

g)

YIELD

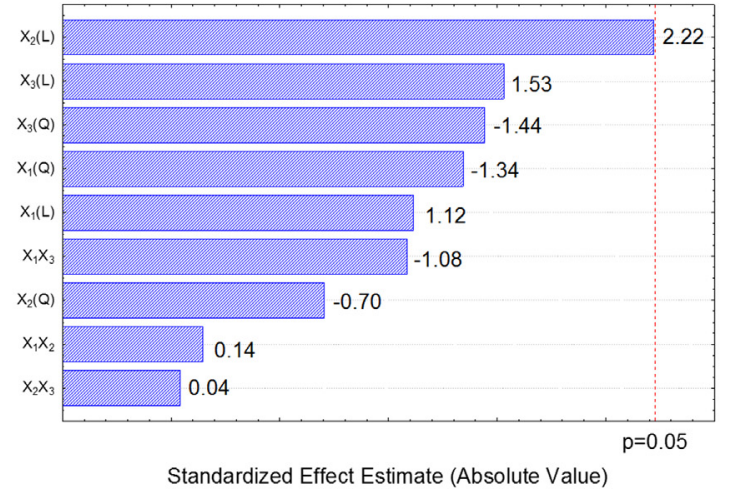

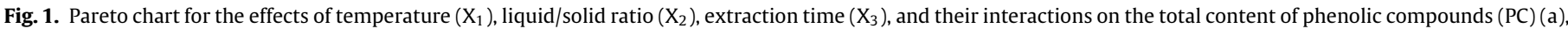

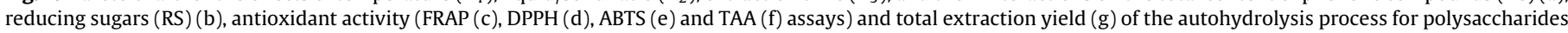

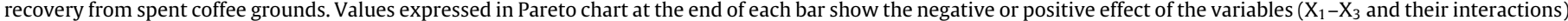

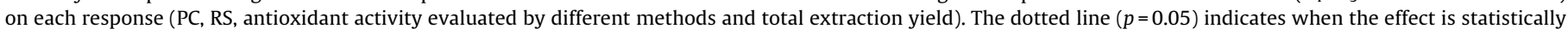
significant, with a confidence level of $95 \%$. 

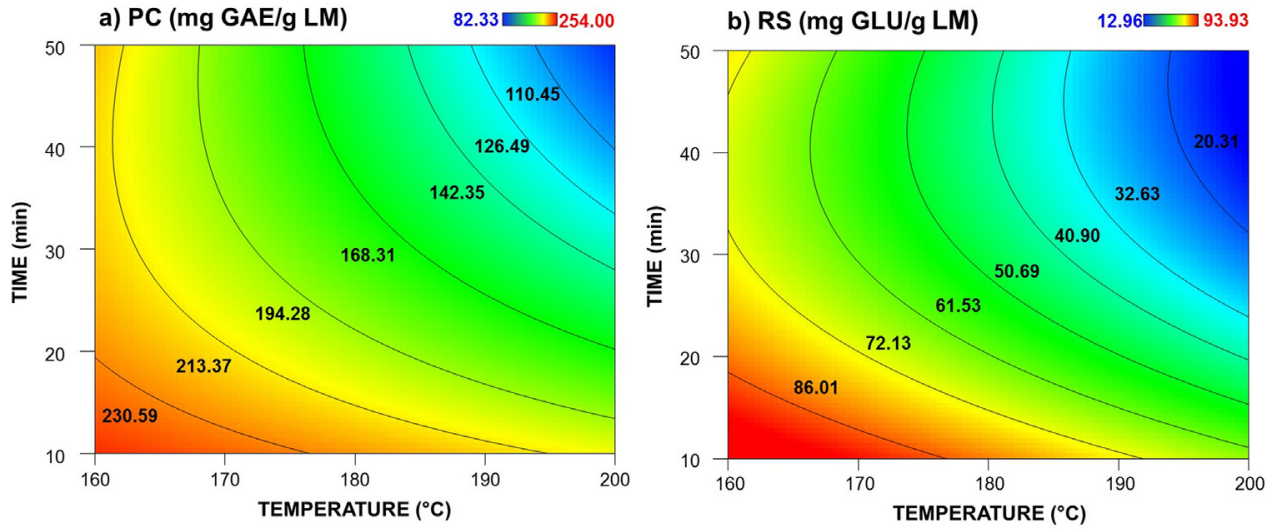

c) FRAP (mmol Fe(II)/g LM)

$0.20 \longleftarrow 0.70$
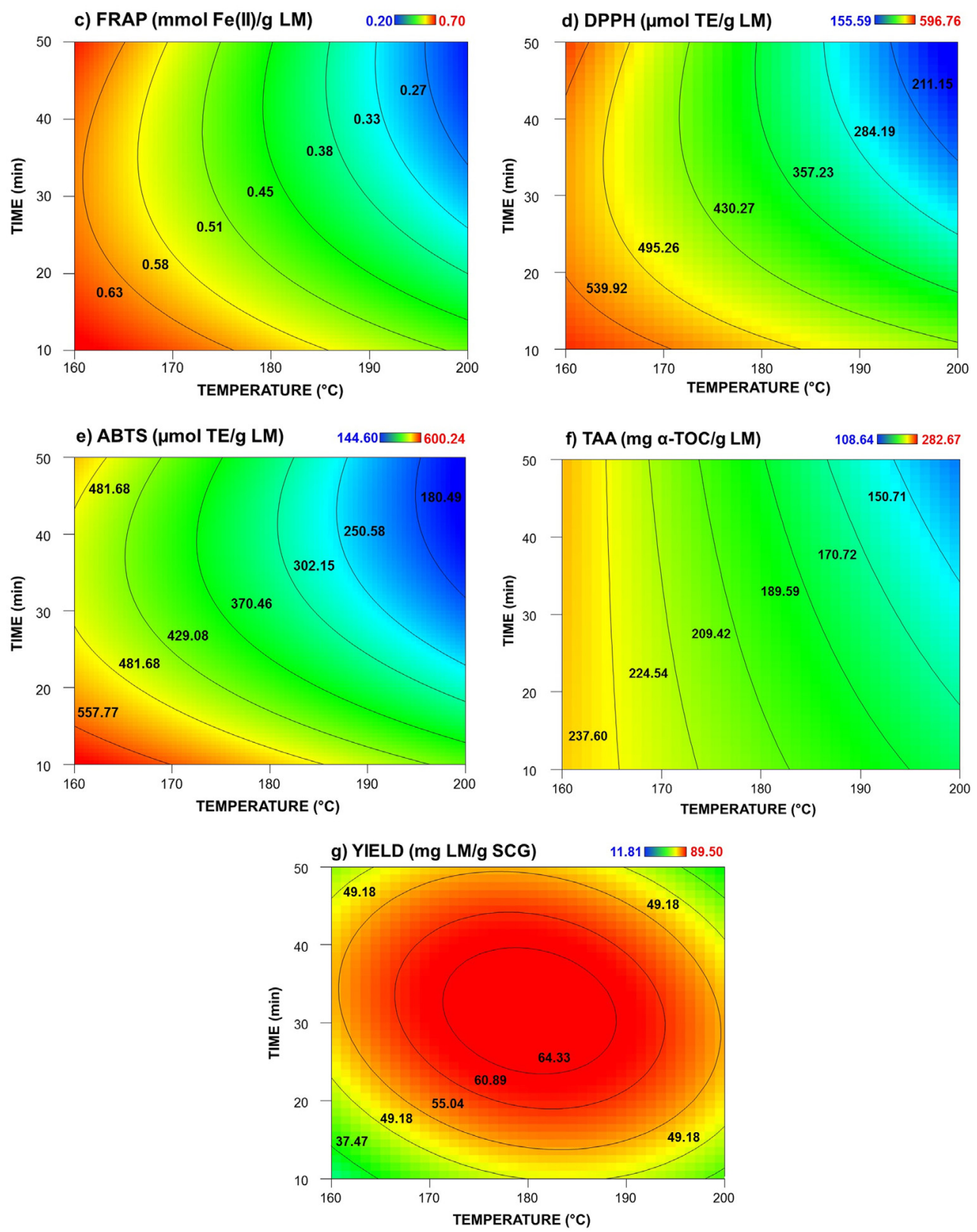

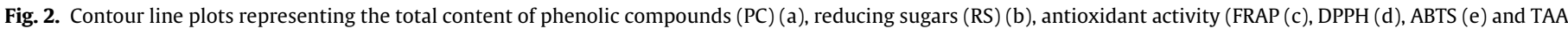

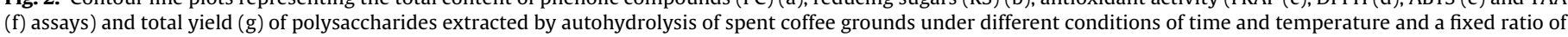
$15 \mathrm{ml} / \mathrm{g} \mathrm{SCG}$. 
Table 2

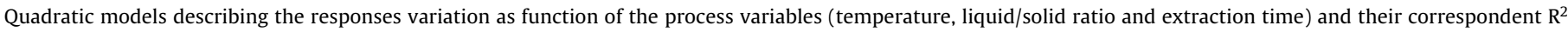
coefficients.

\begin{tabular}{|c|c|c|}
\hline Response $^{\text {a }}$ & Model equation ${ }^{\mathrm{b}}$ & $\mathrm{R}^{2}$ \\
\hline PC (mg GAE/g LM) & $\mathrm{PC}=178.13-41.95 \mathrm{X}_{1}-35.95 \mathrm{X}_{3}-23.11 \mathrm{X}_{1} \mathrm{X}_{3}+13.29 \mathrm{X}_{3}^{2}$ & 0.94 \\
\hline $\mathrm{RS}$ (mg GLU/g LM) & $\mathrm{RS}=46.47-20.68 \mathrm{X}_{1}+1.82 \mathrm{X}_{2}-20.14 \mathrm{X}_{3}-4.58 \mathrm{X}_{1} \mathrm{X}_{2}-6.87 \mathrm{X}_{1} \mathrm{X}_{3}+14.67 \mathrm{X}_{3}^{2}$ & 0.96 \\
\hline Yield (mg LM/g SCG) & Yield $=56.04+0.55 \mathrm{X}_{1}+10.62 \mathrm{X}_{2}+2.41 \mathrm{X}_{3}-4.35 \mathrm{X}_{1} \mathrm{X}_{3}-12.70 \mathrm{X}_{1}^{2}-15.04 \mathrm{X}_{3}^{2}$ & 0.93 \\
\hline \multicolumn{3}{|l|}{ Antioxidant activity } \\
\hline FRAP (mmol Fe(II)/g LM) & FRAP $=0.46-0.14 \mathrm{X}_{1}+0.0008 \mathrm{X}_{2}-0.10 \mathrm{X}_{3}-0.03 \mathrm{X}_{1} \mathrm{X}_{2}-0.07 \mathrm{X}_{1} \mathrm{X}_{3}+0.02 \mathrm{X}_{2} \mathrm{X}_{3}+0.07 \mathrm{X}_{3}^{2}$ & 0.97 \\
\hline DPPH ( $\mu \mathrm{mol}$ TE/g LM) & $\mathrm{DPPH}=375.34-100.27 \mathrm{X}_{1}+8.32 \mathrm{X}_{2}-78.76 \mathrm{X}_{3}-40.09 \mathrm{X}_{1} \mathrm{X}_{2}-72.93 \mathrm{X}_{1} \mathrm{X}_{3}+46.50 \mathrm{X}_{3}^{2}$ & 0.90 \\
\hline ABTS ( $\mu \mathrm{mol} \mathrm{TE} / \mathrm{g}$ LM) & ABTS $=319.09-110.72 X_{1}+11.45 X_{2}-91.91 X_{3}-31.49 X_{1} X_{2}-45.17 X_{2} X_{3}+86.25 X_{3}{ }^{2}$ & 0.95 \\
\hline TAA (mg $\alpha-T O C / g$ LM) & $\mathrm{TAA}=199.60-41.81 \mathrm{X}_{1}+2.84 \mathrm{X}_{2}-32.03 \mathrm{X}_{3}-4.65 \mathrm{X}_{1} \mathrm{X}_{2}-13.57 \mathrm{X}_{1} \mathrm{X}_{3}+20.32 \mathrm{X}_{2} \mathrm{X}_{3}$ & 0.87 \\
\hline
\end{tabular}

a PC: phenolic compounds; RS: reducing sugars; Yield: yield of extraction process; FRAP: antioxidant activity by the ferric reducing antioxidant power assay; DPPH:

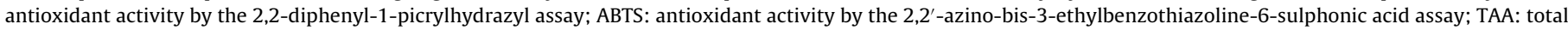
antioxidant activity. LM: lyophilized material.

b $\mathrm{X}_{1}$ : temperature; $\mathrm{X}_{2}$ : liquid/solid ratio; $\mathrm{X}_{3}$ : extraction time. Coded values.

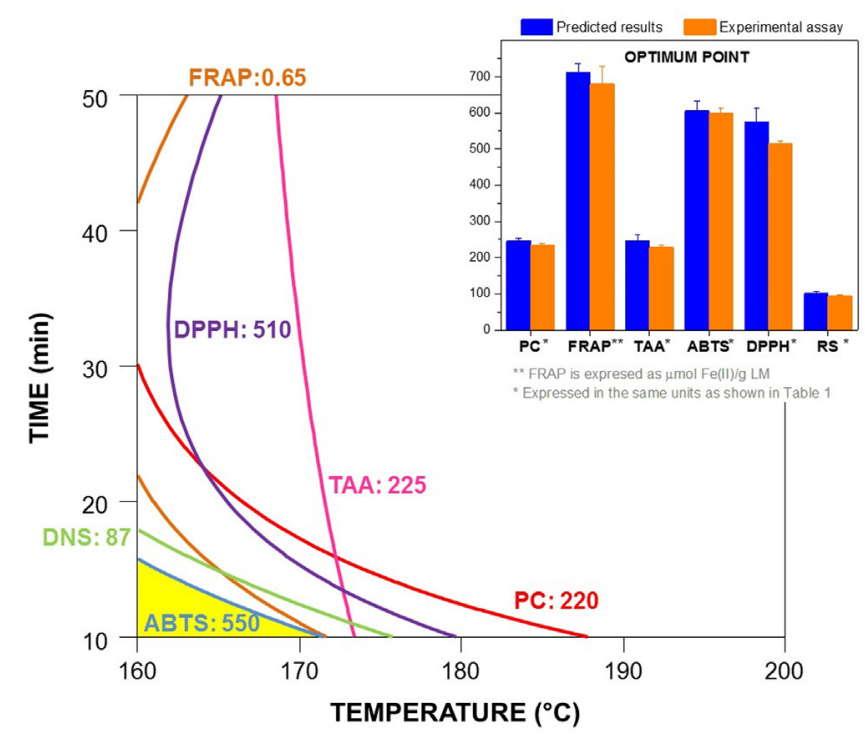

Fig. 3. Optimum region plot obtained by overlaying the curves of the responses phenolic compounds (PC), reducing sugars (RS) and antioxidant activity by FRAP, $\mathrm{DPPH}, \mathrm{ABTS}$ and TAA assays as a function of the extraction time and temperature used during the autohydrolysis process, and comparison between the predicted and experimental results (inset figure).

\subsection{Optimum point characterization}

\subsubsection{Yield of extraction and sugars composition}

The sugars content in the polysaccharides extracted under the conditions of the optimum point and best yield, as well as the yields obtained for each one of these processes, are shown in Table 3. In this table, Y1 corresponds to the total yield of extraction ( $\mathrm{g}$ LM per $100 \mathrm{~g}$ SCG); Y2 refers to the quantity of sugars present in LM per $100 \mathrm{~g}$ SCG; while Y3 represents the yield of sugars extracted with respect to total sugars existent in SCG (g total sugars in LM/100 g of sugars from SCG).

The content of total sugars recovered was $29.29 \%$ and $33.25 \%$ $(\mathrm{w} / \mathrm{w})$ for the optimum point and best yield samples, respectively. Although the amount of sugar in both samples was similar, Y1-Y3 were 2-fold higher for the best yield sample, achieving 8.95, 2.97 and $5.72 \%(\mathrm{w} / \mathrm{w})$. Analysis of the monosaccharide composition (Table 3 ) revealed a structural difference between the polysaccharides samples. However, galactose was the main monosaccharide and arabinose the less representative sugar for both, optimum point and best yield samples. The high content of galactose in both samples $(47 \% \mathrm{~mol})$ allows concluding that polysaccharides recovered under the optimum point and the best yield conditions include arabinogalactans and galactomannans. The quantity of mannose in the optimum point sample $(31.88 \% \mathrm{~mol})$ was more represen- tative than in the best yield sample, suggesting the presence of higher amount of galactomannans in the optimum point sample. Another structural difference between these two polysaccharides is the percentage of reducing sugars with respect to the percentage of total sugars, being $33 \%(\mathrm{w} / \mathrm{w})$ and $15 \%(\mathrm{w} / \mathrm{w})$ for optimum point and the best yield samples, respectively. Thus, the sugars obtained under the best yield conditions are mainly polysaccharides of long chains, while the sugars recovered under optimum point conditions are made up in a great part of oligosaccharides and/or short chain polysaccharides.

Taking into account the composition of sugars in SGC described in other studies (Ballesteros et al., 2014a, 2015; Mussatto, Carneiro et al., 2011; Passos \& Coimbra, 2013), it was expected to find mannose, galactose, arabinose and glucose sugars in the lyophilized material. Nevertheless, the efficiency of the extraction depends on different factors including the variety of the coffee beans and their degree of roasting, solid/liquid ratio, solvent, temperature and extraction time, among others. The percentage of total polysaccharides extracted from SCG by using the autohydrolysis technique was slightly lower when compared to the percentage of total sugars extracted from SCG using alkali pretreatment (Ballesteros et al., 2015; Simões et al., 2009). However, the quantity of mannose extracted $(31.88 \% \mathrm{~mol})$ when using the optimum point conditions was much higher than the amount obtained using the alkaline pretreatment $(4.43 \% \mathrm{~mol})$ (Ballesteros et al., 2015), which shows autohydrolysis as an efficient technique to extract mannose from SCG.

\subsubsection{Structural characterization}

The crystallinity of the extracted polysaccharides was evaluated through X-ray diffraction. Fig. 4a shows the XRD patterns for the optimum point and best yield samples, which were compared with a XRD spectrum of original SCG sample, i.e., not pretreated (Ballesteros et al., 2014a). In general, the optimum point and the best yield polysaccharides samples showed an amorphous behavior, which was expected since the autohydrolysis conditions used are more suitable to extract hemicelluloses. However, the best yield sample presented a broad band, revealing the existence of a small crystalline region in its structure, which can be easily observed when comparing to the cellulose region in the SCG spectrum. Cellulose presents both amorphous and crystalline structures (Park, Baker, Himmel, Parilla, \& Johnson, 2010). Thus, the glucose (cellulose) contents shown in Table 3 refer to the amorphous structure of cellulose, which, together with hemicellulose (mannose, galactose and arabinose) were more easily susceptible to hydrolysis due to the nature of their structure. Although crystalline cellulose hydrolysis requires the use of stronger temperatures and extraction times, the slight crystallinity observed in Fig. 4a for the best extraction yield sample suggests that a small part of crystalline cellulose was 
Table 3

Sugars composition and extraction yield of the polysaccharides obtained by autohydrolysis of spent coffee grounds (SCG).

\begin{tabular}{|c|c|c|c|c|c|c|c|c|}
\hline \multirow[t]{2}{*}{ Sample } & \multicolumn{3}{|c|}{ Yield $^{\mathrm{a}}$} & \multicolumn{4}{|c|}{ Monosaccharide composition (\% mol) } & \multirow[t]{2}{*}{ Total Sugars (\%) } \\
\hline & Y1 & Y2 & Y3 & Arabinose & Mannose & Galactose & Glucose & \\
\hline Optimum point & 3.59 & 1.07 & 2.06 & $10.02 \pm 1.18$ & $31.88 \pm 2.08$ & $47.74 \pm 0.13$ & $10.35 \pm 0.76$ & $29.29 \pm 3.47$ \\
\hline Best yield & 8.95 & 2.97 & 5.72 & $8.05 \pm 1.55$ & $16.93 \pm 1.47$ & $47.32 \pm 1.18$ & $27.68 \pm 1.71$ & $33.25 \pm 0.34$ \\
\hline
\end{tabular}

Results of monosaccharide composition are expressed as mean \pm standard deviation; $\mathrm{n}=3$.

a Y1: total yield of the extraction process using autohydrolysis technique, expressed as g of lyophilized material (LM) per 100 g SCG; Y2: yield in terms of quantity of sugars

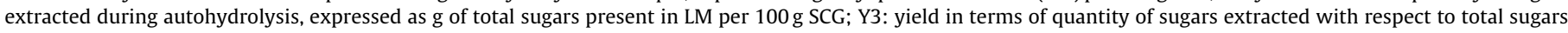
existent in SCG, expressed as $\mathrm{g}$ of total sugars in LM per $100 \mathrm{~g}$ of sugars from SCG.
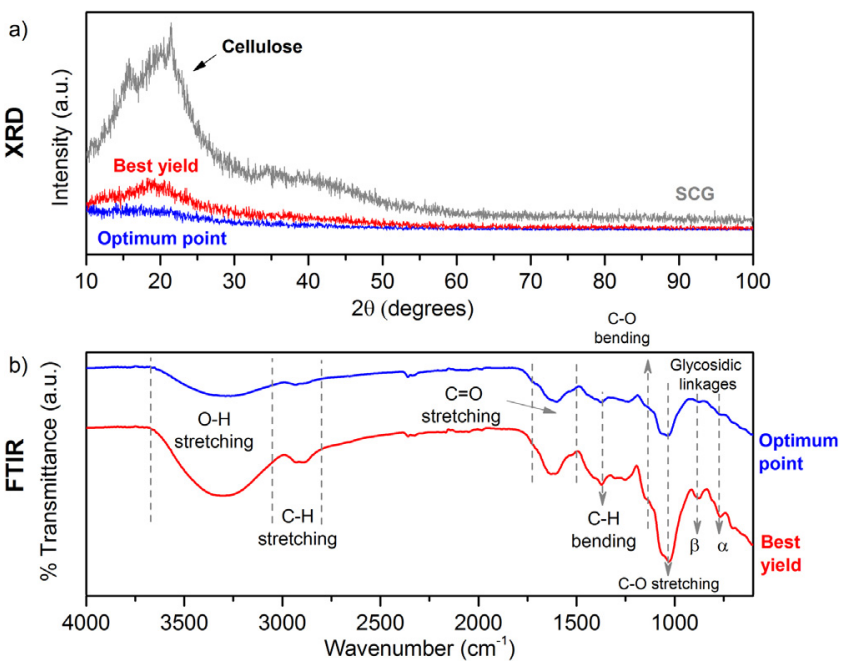

Fig. 4. XRD diffractograms (a) obtained for spent coffee grounds (SCG) and for the polysaccharides extracted by autohydrolysis of SCG using the optimum point and best yield conditions. FTIR spectra (b) obtained for the polysaccharides extracted using the optimum point and best yield conditions.

extracted during the autohydrolysis process when the temperature and extraction time were increased.

The polysaccharides samples were also analyzed by FTIR in order to determine the specific absorption bands present in each lyophilized material. When compared to other IR spectra of polysaccharides reported in the literature, the FTIR spectra obtained for both samples (Fig. 4b) showed a typical carbohydrate pattern behavior (Ballesteros et al., 2015; Cerqueira et al., 2011; Ren et al., 2014). Nevertheless, the magnitude of absorption intensities differed to each sample. The peaks at 778 and $884 \mathrm{~cm}^{-1}$ are related with the presence of $\alpha$-glycosidic and $\beta$-glycosidic linkages, attributed to $\alpha$-D-galactopyranose and $\beta$-D-mannopyranose units, respectively (Cerqueira et al., 2011; Figueiró, Góes, Moreira, \& Sombra, 2004). The broadband between 1191 and $920 \mathrm{~cm}^{-1}$ is related to ring vibrations overlapped with stretching vibrations of $(\mathrm{C}-\mathrm{OH})$ side groups and the $(\mathrm{C}-\mathrm{O}-\mathrm{C})$ glycosidic band vibrations, being specific for polysaccharides. This band showed lower peak intensity for the optimum point when compared to the best yield sample, which is associated with more hydrolyzed sugars (Synytsya \& Novak, 2014), confirming shorter polysaccharides chains for the optimum point sample, as previously mentioned. Additionally, the peak belonging to this band located at $1039 \mathrm{~cm}^{-1}$ results from $\mathrm{C}-\mathrm{O}$ stretching (Ren et al., 2014), and the other peak placed at $1140 \mathrm{~cm}^{-1}$ is related to bending vibrational modes of $\mathrm{C}-\mathrm{O}$ existing in the pyranose form (Figueiró et al., 2004). The peak at $1374 \mathrm{~cm}^{-1}$ corresponds to $\mathrm{C}-\mathrm{H}$ in-plane bending vibration and deformation in cellulose and hemicellulose (Pandey \& Theagarajan, 1997). When the samples show a low crystallinity, there are a decrease or disappearing of some bands in the region of 900-1500 $\mathrm{cm}^{-1}$ (Synytsya \& Novak, 2014). This is evidenced to the optimum point sample, which presents a more amorphous structure when compared to

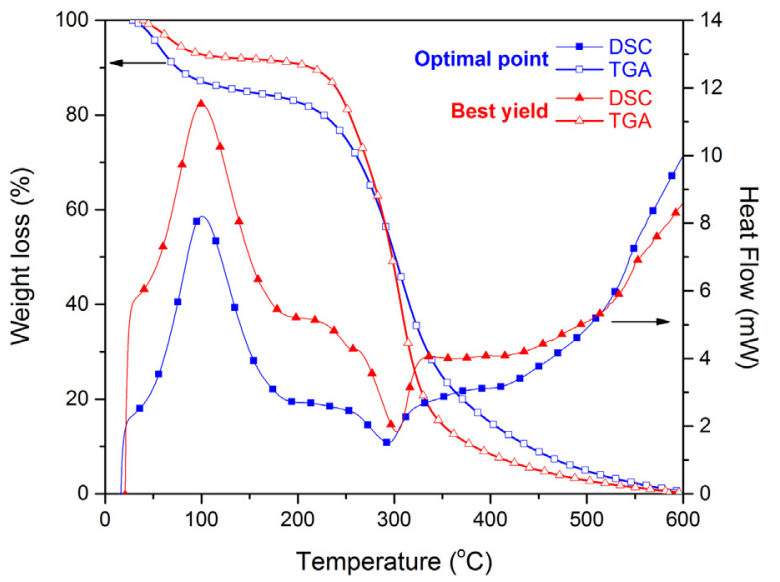

Fig. 5. TGA and DSC curves showing the thermal behavior, chemical changes and weight loss of the polysaccharides extracted from spent coffee grounds under the optimum point and the best yield autohydrolysis conditions.

the best yield sample. The region from 1500 to $1700 \mathrm{~cm}^{-1}$ is related to carbonyl groups $(\mathrm{C}=\mathrm{O})$ asymmetrical and symmetric stretching vibrations (Ren et al., 2014) and to deformation in lignin (Pandey \& Theagarajan, 1997). This band is also highly associated with chlorogenic acids and caffeine (Ribeiro, Salva, \& Ferreira, 2010). Therefore, the peak at $1600 \mathrm{~cm}^{-1}$ could be attributed to a small absorption of these compounds, remaining from the SCG (Ballesteros et al., 2015). The region between 2800 and $3000 \mathrm{~cm}^{-1}$ is related to $\mathrm{C}-\mathrm{H}$ stretching vibration and the broad peak between 3200 and $3600 \mathrm{~cm}^{-1}$ is attributed to the hydroxyl group of $\mathrm{O}-\mathrm{H}$ stretching vibration. The significant lowering of the band intensity in this area indicates the presence of amorphous cellulose (Synytsya and Novak, 2014), being in agreement with the XRD patterns, which revealed that the optimum point sample is less crystalline than the best yield sample (Fig. 4a).

\subsubsection{Thermal properties}

DSC and TGA analyses (Fig. 5) were carried out in order to evaluate the thermal behavior, chemical changes and weight loss of the polysaccharides extracted from SCG under the optimum point and the best yield autohydrolysis conditions. The DSC curves obtained for both samples exhibited two events. The first event, resulting in an endothermic peak and revealed at $100.90^{\circ} \mathrm{C}$ and $99.41^{\circ} \mathrm{C}$ for the optimum point and the best yield samples, respectively, was associated to enthalpy changes of 381.32 and $396.40 \mathrm{~J} / \mathrm{g}$. This event is related to the presence of impurities in the samples and the vaporization of water (indicating the presence of hydrophilic groups), which occurs over a range of temperature. A second event, corresponding to an exothermic transition was observed at $297.73^{\circ} \mathrm{C}$ and $302.60^{\circ} \mathrm{C}$ for the optimum point and the best yield samples respectively, was associated to enthalpy changes of 73.06 and $146.5 \mathrm{~J} / \mathrm{g}$. This event is related to the thermal decomposition of the samples, varying at temperature ranges between 220 and $310^{\circ} \mathrm{C}$ (Ballesteros et al., 2014a). During this event, some differences were observed 
between the samples with respect to enthalpy change, being the value two-fold higher to the best extraction yield condition. Additionally, a slight difference between the degradation temperatures of the samples was noted, indicating that the best yield sample is thermally more stable. This may be due to the structure of the polysaccharides, as well as to the molecular weight, degree of polymerization and branching of the samples (Cerqueira et al., 2011).

The TGA curves (Fig. 5) show the weight losses of the polysaccharides when submitted to severe heating conditions $\left(25-600^{\circ} \mathrm{C}\right)$. Both samples showed similar curves, revealing two weight loss stages. The first one, occurring between 80 and $100^{\circ} \mathrm{C}$, results from the water evaporation (dehydration of the sample) and corresponds to weight losses of about $8.74 \%$ and $6.24 \%$ for the optimum point and the best yield samples, respectively. The greatest transformation and weight losses occurred during the second stage, at approx. $300^{\circ} \mathrm{C}$. At this stage, weight losses of $42.37 \%$ and $57.89 \%$ were observed for the optimum point and best yield samples, respectively, as a consequence of the depolymerization and decomposition of the samples.

\section{Conclusion}

Autohydrolysis was demonstrated to be an efficient technique to recover polysaccharides with high antioxidant activity from SCG, particularly when applied at $160^{\circ} \mathrm{C}$ for $10 \mathrm{~min}$, and using a liquid/solid ratio of $15 \mathrm{ml}$ water/g SCG. Under these conditions, it was possible to obtain a lyophilized material containing $29.29 \%$ (w/w) of polysaccharides, from which galactose was the most representative sugar, followed by mannose, glucose, and arabinose. Additionally, the lyophilized material contained a high content of phenolic compounds (234.14 $07 \mathrm{mg} \mathrm{GAE} / \mathrm{g} \mathrm{LM}$ ) and reducing sugars (93.93 mg GLU/g LM), and presented high antioxidant activity, which as confirmed by four different methods. Furthermore, the polysaccharides presented thermostability in a large range of temperature, being therefore of great interest for industrial applications, mainly in the food industry, for encapsulation of additives or as prebiotics, for example, due to their high antioxidant potential and other functional properties.

\section{Acknowledgements}

The authors acknowledge the financial support of the F̈undação para a Ciência e a Tecnologia (FCT), Portugal through the grant SFRH/BD/80948/2011 and the Strategic Project PEstOE/EQB/LA0023/2013. The authors also thank the Project "BioInd -Biotechnology and Bioengineering for improved Industrial and Agro-Food processes", REF. NORTE-07-0124-FEDER-000028 Cofunded by the Programa Operacional Regional do Norte (ON.2 - O Novo Norte), QREN, FEDER.

\section{References}

Arya, M., \& Rao, L. J. M. (2007). An impression of coffee carbohydrates. Critical Reviews in Food Science and Nutrition, 47, 51-67.

Asano, I., Nakamura, Y., Hoshino, H., Aoki, K., Fujii, S., Imura, N., et al. (2001). Use of mannooligosaccharides from coffee mannan by intestinal bacteria. Nippon Nogeikagaku Kaishi, 75, 1077-1083.

Ballesteros, L. F., Teixeira, J. A., \& Mussatto, S. I. (2014a). Chemical, functional: And structural properties of spent coffee grounds and coffee silverskin. Food and Bioprocess Technology, 7, 3493-3503.

Ballesteros, L. F., Teixeira, J. A., \& Mussatto, S. I. (2014b). Selection of the solvent and extraction conditions for maximum recovery of antioxidant phenolic compounds from coffee silverskin. Food and Bioprocess Technology, 7 $1322-1332$.

Ballesteros, L. F., Cerqueira, M. A., Teixeira, J. A., \& Mussatto, S. I. (2015). Characterization of polysaccharides extracted from spent coffee grounds by alkali pretreatment. Carbohydrate Polymers, 127, 347-354.

Cerqueira, M. A., Souza, B. W., Simões, J., Teixeira, J. A., Domingues, M. R. M., Coimbra, M. A., et al. (2011). Structural and thermal characterization of galactomannans from non-conventional sources. Carbohydrate Polymers, 83, 179-185.

Clark, T. A., \& Mackie, K. L. (1984). Fermentation inhibitors in wood hydrolysates derived from the softwood Pinus radiata. Journal of Chemical Technology and Biotechnology. Biotechnology, 34, 101-110.

Conde, T., \& Mussatto, S. I. (2016). Isolation of polyphenols from spent coffee grounds and silverskin by mild hydrothermal pretreatment. Preparative Biochemistry and Biotechnology, http://dx.doi.org/10.1080/10826068.2015. 1084514

Figueiró, S., Góes, J. C., Moreira, R., \& Sombra, A. (2004). On the physico-chemical and dielectric properties of glutaraldehyde crosslinked galactomannan-collagen films. Carbohydrate Polymers, 56, 313-320.

Fischer, M., Reimann, S., Trovato, V., \& Redgwell, R. J. (2001). Polysaccharides of green Arabica and Robusta coffee beans. Carbohydrate Research, 330, 93-101.

Gniechwitz, D., Reichardt, N., Blaut, M., Steinhart, H., \& Bunzel, M. (2007). Dietary fiber from coffee beverage: degradation by human fecal microbiota. Journal of Agricultural and Food Chemistry, 55, 6989-6996.

Gotoda, N., Iwai, K., Furuya, K., Ueda, T., Fukunaga, T., Kimura, R., et al. (2007). Arabinogalactan isolated from coffee beans indicates immunomodulating properties. In Paper Presented at the 21 st International Conference on Coffee Science.

Mussatto, S. I., Carneiro, L. M., Silva, J., Roberto, I. C., \& Teixeira, J. A. (2011). A study on chemical constituents and sugars extraction from spent coffee grounds. Carbohydrate Polymers, 83, 368-374.

Mussatto, S. I., Machado, E. M. S., Martins, S., \& Teixeira, J. A. (2011). Production: Composition and application of coffee and its industrial residues. Food and Bioprocess Technology, 4, 661-672.

Nabarlatz, D., Ebringerová, A., \& Montané, D. (2007). Autohydrolysis of agricultural by-products for the production of xylo-oligosaccharides. Carbohydrate Polymers, 69, 20-28.

Nunes, F. M., Domingues, M. R., \& Coimbra, M. A. (2005). Arabinosyl and glucosyl residues as structural features of acetylated galactomannans from green and roasted coffee infusions. Carbohydrate Research, 340, 1689-1698.

Oosterveld, A., Harmsen, J., Voragen, A., \& Schols, H. (2003). Extraction and characterization of polysaccharides from green and roasted Coffea arabica beans. Carbohydrate Polymers, 52, 285-296.

Pandey, K., \& Theagarajan, K. (1997). Analysis of wood surfaces and ground wood by diffuse reflectance (DRIFT) and photoacoustic (PAS) Fourier transform infrared spectroscopic techniques. Holz als Roh-und Werkstof, 55, 383-390.

Park, S., Baker, J. O., Himmel, M. E., Parilla, P. A., \& Johnson, D. K. (2010). Research cellulose crystallinity index: measurement techniques and their impact on interpreting cellulase performance. Biotechnology for Biofuels, 3, 1-10.

Passos, C. P., \& Coimbra, M. A. (2013). Microwave superheated water extraction of polysaccharides from spent coffee grounds. Carbohydrate Polymers, 94 , 626-633.

Ren, L., Hemar, Y., Perera, C. O., Lewis, G., Krissansen, G. W., \& Buchanan, P. K. (2014). Antibacterial and antioxidant activities of aqueous extracts of eight edible mushrooms. Bioactive Carbohydrates and Dietary Fibre, 3, 41-51.

Ribeiro, J. S., Salva, T. J., \& Ferreira, M. (2010). Chemometric studies for quality control of processed Brazilian coffees using DRIFTS. Journal of Food Quality, 33, 212-227.

Rivas, S., Conde, E., Moure, A., Domínguez, H., \& Parajó, J. C. (2013). Characterization: refining and antioxidant activity of saccharides derived from hemicelluloses of wood and rice husks. Food Chemistry, 141, 495-502.

Romaní, A., Garrote, G., López, F., \& Parajó, J. C. (2011). Eucalyptus globulus wood fractionation by autohydrolysis and organosolv delignification. Bioresource Technology, 102, 5896-5904.

Simões, J., Madureira, P., Nunes, F. M., do Rosário Domingues, M., Vilanova, M., \& Coimbra, M. A. (2009). Immunostimulatory properties of coffee mannans. Molecular Nutrition E' Food Research, 53, 1036-1043.

Simões, J., Nunes, F. M., Maria do Rosário, M. D., \& Coimbra, M. A. (2010). Structural features of partially acetylated coffee galactomannans presenting immunostimulatory activity. Carbohydrate Polymers, 79, 397-402.

Simões, J., Maricato, Nunes, F. M., Domingues, M. R., \& Coimbra, M. A. (2014) Thermal stability of spent coffee ground polysaccharides: Galactomannans and arabinogalactans. Carbohydrate Polymers, 101, 256-264.

Synytsya, A., \& Novak, M. (2014). Structural analysis of glucans. Annals of Translational Medicine, 2(2), 17. http://dx.doi.org/10.3978/j.issn.2305-5839. 2014.02.07 